\title{
Sustainable Decision-Making using the COMET Method: An Empirical Study of the Ammonium Nitrate Transport Management
}

\author{
Jarosław Wątróbski*§, Wojciech Sałabun*, Artur Karczmarczyk* and Waldemar Wolski ${ }^{\dagger}$ \\ ${ }^{*}$ West Pomeranian University of Technology in Szczecin \\ ul. Żołnierska 49, 71-210 Szczecin, Poland \\ $\dagger$ University of Szczecin \\ ul. Mickiewicza 64, 71-101 Szczecin, Poland \\ $\S$ corresponding author
}

\begin{abstract}
This paper investigates the problem of the sustainable ammonium nitrate transport. The significance of this problem is increasing, considered the occurrence of the worldwide agricultural production boost. The existing international regulations for the transport of the dangerous chemical substances are not sufficient to obtain a satisfactory solution for the sustainable transport. The main reason for that is the fact that the safety criteria can easily become dominated by the economic factors.

In this paper, the authors use the COMET method to identify a decision making model for the selection of the best scenario of sustainable transport. The COMET method is a new multicriteria decision-making technique that is free of the rank reversal phenomenon. The identified model provides information about the global and local significance level of each of the criteria. The proposed approach can be easily expanded by using a greater number of criteria, depending on the particular problem analyzed. The proposed methodology is an efficient and highly accurate solution to make decisions based on experts' knowledge.
\end{abstract}

\section{INTRODUCTION}

T HE ammonium nitrate is one of the most popular mineral fertilizers in Poland and in Europe. It supports a highly developed agricultural industry [1], [2]. The carriage of the ammonium nitrate is regulated by international legal standards due to its dangerous nature [3]. The process of the registration of the transport of the ammonium nitrate and its classification to a group of hazardous materials determines a number of guidelines on its transport [4]. The obligation to ensure the compliance of the carriage of the ammonium nitrate with international laws and regulations for transporting dangerous materials by rail (RID - Réglement concernant le transport International ferroviaire des marchandises Dangereuses) and road (ADR - L' Accord européen relatif au transport international des marchandises Dangereuses par Route), affects the final time and cost of the transport of the product [4], [5].

The sustainable transportation systems should not only be efficient, robust and economical, but also friendly towards the environment, which is the requirement of the modern times [6]. They should minimize the impact on the environment, such as air pollution, noise, etc [7]. The evaluation and selection of the best scenario for the transportation system is a big challenge. Many popular evaluation methods, such as Economic-Effects Analysis (EEA), private investment analysis and CBA, are considering mainly the economic effects [8], sometimes neglecting the ecological, spatial or social aspects of the transport scenario [9]. Even if those latter aspects are taken into account, for example in a Social Cost-Benefit Analysis (SCBA), it remains difficult to obtain a monetary assessment of all the criteria [10]. This challenge can be solved with a usage of appropriate multi-criteria decision making (MCDM) methods, which are frequently used in transportation systems' management problems [11], [12].

Generally, the MCDA methods can be divided into two groups: American and European schools. The former are based on a functional approach - a utility or value function is used [13], [14]. Two types of relationship among the alternatives are used in these methods, namely, the indifference and the preference. The incomparabilities of the variants are skipped. The pronounced downside of these methods is the fact that they do not consider the expert judgements' variability and uncertainty [15]. The methods from the latter group are based on a relational model. The relations of weak or strong preference, indifference or incomparabily are used most commonly [16], and the outranking relation is used in the aggregation process to provide the final rankings of the studied alternatives [17]. Unfortunately, although the ranking of alternatives is produced in the European school methods, the quantitative information on the differences between alternatives is often lost.

Apart from the aforementioned groups of methods, there has also been some research that connects the MCDA approach of both of them [18]. Additionaly, methods based on a rule sets exist. A range of the MCDA methods, along with their assignment to the American, European, mixed or rule set approach, is presented in Table I.

The MCDA methods from all the aforementioned groups have been successfully used to facilitate decision making in various kinds of transport management: land [49], [50], [55], maritime [47], [54] and air [27] transport. Some of the researched transport management decision problems also included the carriage of hazardous materials [55]. A comparison 
TABLE I

MCDA METHODS FROM AMERICAN AND EUROPEAN SCHOOLS, MIXED AND RULE SET BASED.

\begin{tabular}{|c|c|c|c|c|}
\hline School & Method Name & Abbreviation & Preference relations & References \\
\hline \multirow{8}{*}{ American } & multi-attribute utility theory & MAUT & indifference, preference & [19] \\
\hline & multi-attribute value theory & MAVT & indifference, preference & [20] \\
\hline & analytic hierarchy process & AHP & indifference, preference & [21] \\
\hline & analytic network process & ANP & indifference, preference & {$[22]$} \\
\hline & simple multi-attribute rating technique & SMART & indifference, preference & [23] \\
\hline & utility theory additive & UTA & indifference, preference & [24] \\
\hline & $\begin{array}{l}\text { measuring attractiveness by a categorical based evaluation tech- } \\
\text { nique }\end{array}$ & MACBETH & indifference, preference & {$[25],[26],[27]$} \\
\hline & technique for order preference by similarity to ideal solution & TOPSIS & indifference, preference & {$[28]$} \\
\hline \multirow{9}{*}{ European } & $\begin{array}{l}\text { ELimination Et Choix Traduisant la REalit'e (ELimination and } \\
\text { Choice Expressing the REality) }\end{array}$ & ELECTRE & incomparability, outranking & [29], [30] \\
\hline & $\begin{array}{l}\text { Preference Ranking Organization METHod for Enrichment of } \\
\text { Evaluations }\end{array}$ & PROMETHEE & $\begin{array}{l}\text { indifference, preference, incom- } \\
\text { parability }\end{array}$ & [31] \\
\hline & $\begin{array}{l}\text { Novel Approach to Imprecise Assessment and Decision Envi- } \\
\text { ronment }\end{array}$ & NAIADE & incomparability, outranking & {$[32]$} \\
\hline & $\begin{array}{l}\text { Organisation, Rangement Et Synthese de donnees relaTion- } \\
\text { nElles }\end{array}$ & ORESTE & $\begin{array}{l}\text { indifference, preference, incom- } \\
\text { parability }\end{array}$ & [33] \\
\hline & REGIME & REGIME & incomparability, outranking & [34] \\
\hline & ARGUS & ARGUS & $\begin{array}{l}\text { indifference, incomparability, } \\
\text { outranking }\end{array}$ & [35] \\
\hline & $\begin{array}{l}\text { Treatment of the Alternatives according To the Importance of } \\
\text { Criteria }\end{array}$ & TACTIC & $\begin{array}{l}\text { indifference, preference, incom- } \\
\text { parability }\end{array}$ & {$[36]$} \\
\hline & $\begin{array}{l}\text { Methode d'Elimination et de Choix Incluant les relation } \\
\text { d'ORdre }\end{array}$ & MELCHIOR & incomparability, outranking & {$[36],[37]$} \\
\hline & $\begin{array}{l}\text { Procedure d'Agregation Multicritere de type Surclassement de } \\
\text { Synthese pour Evaluations Mixtes }\end{array}$ & PAMSSEM & incomparability, outranking & [38] \\
\hline \multirow{6}{*}{ mixed } & $\begin{array}{l}\text { Multicriteria Evaluation with MixedQualitative and Quantitative } \\
\text { Data }\end{array}$ & EVAMIX & indifference, preference & [39] \\
\hline & QUALItative FLEXible multiple criteria method & QUALIFLEX & incomparability, outranking & [40] \\
\hline & $\begin{array}{l}\text { (Multicriterion Analysis of Preferences by means of Pair- } \\
\text { wiseActions and Criterion comparisons }\end{array}$ & MAPPAC & $\begin{array}{l}\text { indifference, preference, weak } \\
\text { preference, incomparability }\end{array}$ & [16] \\
\hline & $\begin{array}{l}\text { Preference Ranking Globalfrequencies in Multicriterion Analy- } \\
\text { sis }\end{array}$ & PRAGMA & $\begin{array}{l}\text { indifference, preference, incom- } \\
\text { parability }\end{array}$ & {$[16]$} \\
\hline & Passive and Active Compensability MulticriteriaAnalysis & PACMAN & $\begin{array}{l}\text { indifference, preference, weak } \\
\text { preference, incomparability }\end{array}$ & [41] \\
\hline & Intercriteria Decision Rule Approach & IDRA & indifference, preference & [42] \\
\hline \multirow{2}{*}{ rule set } & Characteristic Objects Method & COMET & indifference, preference & [43] \\
\hline & Dominance-based Rough Set Approach & DRSA & $\begin{array}{l}\text { Indifference, preference, weak } \\
\text { preference, incomparability }\end{array}$ & {$[44]$} \\
\hline
\end{tabular}

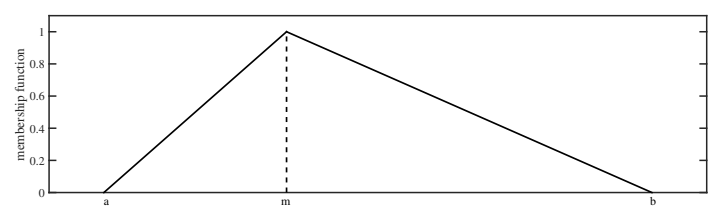

Fig. 1. An example of a triangular fuzzy number with the support $[a, b]$ and the core $m$.

of selected approaches of the MCDA methods' application in the transport management decision-making is presented in Table II. A further literature review can be found inter alia in [6], [57] and [58].

Unfortunately, the classical MCDM methods are often criticized for their possible shortcomings, such as the rank reversal phenomenon [59]. Therefore, new MCDM approaches have been developed to avoid the identified flaws. One of the issues considered is the fact that the decisions are often being made on the basis of multiple conflicting information sources. Based on these premises, a new MCDA method, Characteristic Objects METhod (COMET) has been developed, which is completely free of the Rank Reversal phenomenon [60].

The rest of this paper is organized as follows: in the next section, the Fuzzy Set Theory preliminaries are outlined. The third section describes the COMET method as a tool to identify the decision models. Subsequently, in section IV, an experiment to build a decision model for an exemplary ammonium nitrate transport is described and the results are presented. The conclusions and the possible future directions are presented in section $\mathrm{V}$.

\section{FuZZy Set Theory: Preliminaries}

The development of fuzzy set theory was initiated by Lofti Zadeh, who presented the idea and the first conception of fuzzy sets in his "Fuzzy Sets" paper [61]. Today, the fuzzy set theory is a very important approach to the control and model creation in various scientific fields. Modeling with the usage of the fuzzy sets has proven to be an effective way to formulate the multi-criteria decision problems [62], [63], [64]. The basic notions and concepts of the Fuzzy Set Theory are defined below [65], [66], [67]:

Definition 1 The fuzzy set and the membership function 
TABLE II

SAMPLE APPLICATIONS OF MCDA METHODS IN TRANSPORT MANAGEMENT SUSTAINABLE DECISION PROBLEMS.

\begin{tabular}{|c|c|c|c|c|}
\hline Method & Application & Number of alternatives & Number of criteria & Reference \\
\hline AHP & $\begin{array}{l}\text { Selection of a location and design of a highway in a metropoli- } \\
\tan \text { area. }\end{array}$ & 4 & 6 & [45] \\
\hline AHP & $\begin{array}{l}\text { Selection of transportation fuels and policy for Singapore land } \\
\text { transport. }\end{array}$ & 10 & 6 & [46] \\
\hline AHP / EVAMIX & $\begin{array}{l}\text { Evaluation of AGV Fleet Operation at Port Container Terminal. } \\
\text { An attept to increase of a container terminal productivity in } \\
\text { order to reduce ship turnaround times. }\end{array}$ & 12 scenarios & - & [47] \\
\hline AHP / TOPSIS & Selection of alternative fuels for public transportation. & 12 & 11 & [48] \\
\hline ANP & Selection of a third party logistic service provider. & - & 23 & [49] \\
\hline ANP & Selection of a supplier. & - & 10 & {$[50]$} \\
\hline Fuzzy AHP & $\begin{array}{l}\text { Evaluation of environmental effects of } 5 \text { different transport } \\
\text { modes. }\end{array}$ & 5 & 9 & {$[51]$} \\
\hline Fuzzy TOPSIS & $\begin{array}{l}\text { A methodology to support the outsourcing of the logistic } \\
\text { services to third parties. }\end{array}$ & 3 & 12 & {$[52]$} \\
\hline Fuzzy TOPSIS & Selection of the locations for urban distribution centers. & 3 & 11 & [53] \\
\hline Fuzzy VIKOR & $\begin{array}{l}\text { Creation of a decision-making model for the choice of a green } \\
\text { reverse logistics solution. }\end{array}$ & 6 & 5 & [7] \\
\hline MACBETH & $\begin{array}{l}\text { Evaluation of air transport performance and efficiency. Self- } \\
\text { benchmarking study of } 3 \text { airports. }\end{array}$ & - & 8 & {$[26]$} \\
\hline MACBETH & $\begin{array}{l}\text { Airlines Performance and Eflciency Evaluation, comparison of } \\
\text { low cost carriers and legacy carriers. }\end{array}$ & 6 & 18 & [27] \\
\hline MAPPAC / FANP & $\begin{array}{l}\text { An integrated MAPPAC / FANP approach to the performance } \\
\text { assessment of the Iranian maritime container terminals was } \\
\text { researched. }\end{array}$ & 6 & 18 & [54] \\
\hline ORESTE & $\begin{array}{l}\text { A multi-criteria and multi-actor MCDA decision problem on the } \\
\text { nuclear waste management. }\end{array}$ & 27 actions & 4 & {$[55]$} \\
\hline TOPSIS & $\begin{array}{l}\text { Assessment of the improvement areas in the implementation of } \\
\text { the green supply chain initiatives. }\end{array}$ & 3 & 16 & {$[56]$} \\
\hline
\end{tabular}

The characteristic function $\mu_{A}$ of a crisp set $A \subseteq X$ assigns a value of either 0 or 1 to each member of $X$, as well as the crisp sets only allow a full membership $\left(\mu_{A}(x)=1\right)$ or no membership at all $\left(\mu_{A}(x)=0\right)$. This function can be generalized to a function $\mu_{\tilde{A}}$ so that the value assigned to the element of the universal set $X$ falls within a specified range, i.e., $\mu_{\tilde{A}}: X \rightarrow[0,1]$. The assigned value indicates the degree of membership of the element in the set A. The function $\mu_{\tilde{A}}$ is called a membership function and the set $\tilde{A}=\left\{\left(x, \mu_{\tilde{A}}(x)\right)\right\}$, where $x \in X$, defined by $\mu_{\tilde{A}}(x)$ for each $x \in X$, is called a fuzzy set [68], [69].

Definition 2 The triangular fuzzy number (TFN)

A fuzzy set $\tilde{A}$, defined on the universal set of real numbers $\Re$, is told to be a triangular fuzzy number $\tilde{A}(a, m, b)$ if its membership function has the following form (1) [68]:

$$
\mu_{\tilde{A}}(x, a, m, b)= \begin{cases}0 & x \leq a \\ \frac{x-a}{m-a} & a \leq x \leq m \\ 1 & x=m \\ \frac{b-x}{b-m} & m \leq x \leq b \\ 0 & x \geq b\end{cases}
$$

and the following characteristics (2), (3):

$$
\begin{aligned}
& x_{1}, x_{2} \in[a, b] \wedge x_{2}>x_{1} \Rightarrow \mu_{\tilde{A}}\left(x_{2}\right)>\mu_{\tilde{A}}\left(x_{1}\right) \\
& x_{1}, x_{2} \in[b, c] \wedge x_{2}>x_{1} \Rightarrow \mu_{\tilde{A}}\left(x_{2}\right)<\mu_{\tilde{A}}\left(x_{1}\right)
\end{aligned}
$$

An example of triangular fuzzy number $\tilde{A}(a, m, b)$ is presented on Figure 1.

Definition 3 The support of a TFN $\tilde{A}$
The support of a TFN $\tilde{A}$ is defined as a crisp subset of the $\tilde{A}$ set in which all elements have a non-zero membership value in the $\tilde{A}$ set (4):

$$
S(\tilde{A})=\left\{x: \mu_{\tilde{A}}(x)>0\right\}=[a, b]
$$

Definition 4 The core of a TFN $\tilde{A}$

The core of a TFN $\tilde{A}$ is a singleton (one-element fuzzy set) with the membership value equal to $1(5)$ :

$$
C(\tilde{A})=\left\{x: \mu_{\tilde{A}}(x)=1\right\}=m
$$

Definition 5 The fuzzy rule

The single fuzzy rule can be based on the Modus Ponens tautology [68], [69]. The reasoning process uses the $I F-T H E N, O R$ and $A N D$ logical connectives.

Definition 6 The rule base

The rule base consists of logical rules determining the causal relationships existing in the system between the input and output fuzzy sets [69], [70].

Definition 7 The T-norm operator: product

The T-norm operator is a $T$ function modeling the $A N D$ intersection operation of two or more fuzzy numbers, e.g. $\tilde{A}$ and $\tilde{B}$. In this paper, only the ordinary product of real numbers is used as the T-norm operator [68], [69], [70] (6):

$$
\mu_{\tilde{A}}(x) \quad A N D \quad \mu_{\tilde{B}}(y)=\mu_{\tilde{A}}(x) \cdot \mu_{\tilde{B}}(y)
$$

III. The Characteristic ObJects Method

The COMET method is completely free of the Rank Reversal phenomenon. The basic concept of the COMET method 
was proposed by prof. Piegat [69]. In the previous works, the accuracy of the COMET method was verified [71]. The formal notation of the COMET method should be briefly recalled [65], [66], [67].

Step 1. Definition of the space of the problem - the expert determines the dimensionality of the problem by selecting $r$ criteria, $C_{1}, C_{2}, \ldots, C_{r}$. Then, a set of fuzzy numbers is selected for each criterion $C_{i}$, e.g. $\left\{\tilde{C}_{i 1}, \tilde{C}_{i 2}, \ldots, \tilde{C}_{i c_{i}}\right\}$ (7):

$$
\begin{aligned}
& C_{1}=\left\{\tilde{C}_{11}, \tilde{C}_{12}, \ldots, \tilde{C}_{1 c_{1}}\right\} \\
& C_{2}=\left\{\tilde{C}_{21}, \tilde{C}_{22}, \ldots, \tilde{C}_{2 c_{2}}\right\} \\
& \cdots \\
& C_{r}=\left\{\tilde{C}_{r 1}, \tilde{C}_{r 2}, \ldots, \tilde{C}_{r c_{r}}\right\}
\end{aligned}
$$

where $c_{1}, c_{2}, \ldots, c_{r}$ are the ordinals of the fuzzy numbers for all criteria.

Step 2. Generation of the characteristic objects - The characteristic objects $(C O)$ are obtained with the usage of the Cartesian product of the fuzzy numbers' cores of all the criteria (8):

$$
C O=C\left(C_{1}\right) \times C\left(C_{2}\right) \times \ldots \times C\left(C_{r}\right)
$$

As a result, an ordered set of all $C O$ is obtained (9):

$$
\begin{aligned}
& C O_{1}=C\left(\tilde{C}_{11}\right), C\left(\tilde{C}_{21}\right), \ldots, C\left(\tilde{C}_{r 1}\right) \\
& C O_{2}=C\left(\tilde{C}_{11}\right), C\left(\tilde{C}_{21}\right), \ldots, C\left(\tilde{C}_{r 2}\right) \\
& \ldots \\
& C O_{t}=C\left(\tilde{C}_{1 c_{1}}\right), C\left(\tilde{C}_{2 c_{2}}\right), \ldots, C\left(\tilde{C}_{r c_{r}}\right)
\end{aligned}
$$

where $t$ is the count of $C O \mathrm{~s}$ and is equal to (10):

$$
t=\prod_{i=1}^{r} c_{i}
$$

Step 3. Evaluation of the characteristic objects - the expert determines the Matrix of Expert Judgment $(M E J)$ by comparing the $C O$ s pairwise. The matrix is presented below:

$$
M E J=\left(\begin{array}{cccc}
\alpha_{11} & \alpha_{12} & \ldots & \alpha_{1 t} \\
\alpha_{21} & \alpha_{22} & \ldots & \alpha_{2 t} \\
\ldots & \ldots & \ldots & \ldots \\
\alpha_{t 1} & \alpha_{t 2} & \ldots & \alpha_{t t}
\end{array}\right)
$$

where $\alpha_{i j}$ is the result of comparing $C O_{i}$ and $C O_{j}$ by the expert. The function $f_{\exp }$ denotes the mental judgment function of the expert. It depends solely on the knowledge of the expert. The expert's preferences can be presented as (12):

$$
\alpha_{i j}= \begin{cases}0.0, & f_{\text {exp }}\left(C O_{i}\right)<f_{\text {exp }}\left(C O_{j}\right) \\ 0.5, & f_{\text {exp }}\left(C O_{i}\right)=f_{\text {exp }}\left(C O_{j}\right) \\ 1.0, & f_{\text {exp }}\left(C O_{i}\right)>f_{\text {exp }}\left(C O_{j}\right)\end{cases}
$$

After the $M E J$ matrix is prepared, a vertical vector of the Summed Judgments $(S J)$ is obtained as follows (13).

$$
S J_{i}=\sum_{j=1}^{t} \alpha_{i j}
$$

Eventually, the values of preference are approximated for each characteristic object. As a result, a vertical vector $P$ is obtained, where the $i-t h$ row contains the approximate value of preference for $C \mathrm{O}_{i}$.

Step 4. The rule base - each characteristic object and its value of preference is converted to a fuzzy rule as follows (14):

$$
\begin{array}{llllllll}
I F & C\left(\tilde{C}_{1 i}\right) & A N D & C\left(\tilde{C}_{2 i}\right) & A N D & \ldots & T H E N & P_{i}
\end{array}
$$

In this way, a complete fuzzy rule base is obtained.

Step 5. Inference and the final ranking - each alternative is presented as a set of crisp numbers, e.g., $A_{i}=\left\{a_{1 i}, a_{2 i}, \ldots, a_{r i}\right\}$. This set corresponds to the criteria $C_{1}, C_{2}, \ldots, C_{r}$. Mamdani's fuzzy inference method is used to compute the preference of the $i-t h$ alternative. The rule base guarantees that the obtained results are unequivocal. The bijection makes the COMET completely rank reversal free.

\section{The Ammonium Nitrate Transport}

The development of the production of the ammonium nitrate, which is one of the most popular fertilizers on the European market, entails the problems of its transport. Poland is one of the five world largest producers of the ammonium nitrate, realizing about $5.5 \%$ of the total world production. The biggest Polish plant producing ammonium nitrate - Zakłady Azotowe "Puławy", plans to expand its production lines by 2020 , thus increasing the production of the fertilizer to the level of 1,200 tons per day.

The paper presents the sustainability model of decision making for transport management scenario where ammonium nitrate is transported from Puławy to Gdańsk. Based on the RID [5] and ADR [4] regulations, a set of 16 possible scenarios of ammonium nitrate transport, $A_{1}-A_{16}$, was prepared. The alternatives $A_{1}-A_{8}$ represent the rail transport scenarios, whereas the alternatives $A_{9}-A_{16}$ represent the road transport scenarios. The scenarios within each of the rail and road groups differ in the type of the container used during the transport. The COMET method and the expert's knowledge was used to create the decision model.

\section{Step 1: Definition of the space of the problem}

Based on the expert's knowledge, the dimensiality of the problem was determined to be equal to $r=3$. The expert pointed out the three most important criteria for the evaluation of the hazardous materials' carriage:

- $C_{1}$ - time required for the transport, including loading and unloading time (in hours);

- $C_{2}$ - transport safety (a value from the range from 0 to 10 , where 0 means low and 10 means high safety);

- $C_{3}$ - the cost of the transport of a single ton, including the cost of loading and unloading (PLN/ton).

The performance table of the alternatives $A_{1}-A_{16}$ and the criteria $C_{1}-C_{3}$ is presented in Table III. It can be observed, that the rail alternatives are slightly cheaper, but significantly slower than the road ones. Regardless of the method of transport chosen, the alternatives using steel crates are characterized 
TABLE III

THE PERFormANCE TABLE OF THE ALTERNATIVES $A_{1}-A_{1} 6$

\begin{tabular}{|c|c|l|c|c|c|c|}
\hline \multirow{2}{*}{ Alternative } & \multirow{2}{*}{ Method } & \multirow{2}{*}{ Container } & \multirow{2}{*}{ Time [h] } & Safety & \multirow{2}{*}{ Cost [PLN/ton] } \\
\cline { 5 - 6 } & & & & Linguistic & Numeric & \\
\hline A1 & RID & cistern & 79 & High & 9 & 320 \\
\hline A2 & RID & in bulk, closed container & 78,5 & High / Medium & 7 & 262 \\
\hline A3 & RID & in bulk, open container & 78 & Medium & 5 & 252 \\
\hline A4 & RID & steel crates & 87 & High & 9 & 1837 \\
\hline A5 & RID & cardboard boxes & 86 & Medium / Low & 3 & 352 \\
\hline A6 & RID & rigid DPPL & 84 & High / Medium & 7 & 932 \\
\hline A7 & RID & elastic DPPL & 85 & Medium & 5 & 262 \\
\hline A8 & RID & plastic canisters & 96 & High / Medium & 7 & 498,6 \\
\hline A9 & ADR & cistern & 14,2 & High & 9 & 426,4 \\
\hline A10 & ADR & in bulk, closed container & 13,6 & High / Medium & 7 & 388 \\
\hline A11 & ADR & in bulk, open container & 13,2 & Medium / Low & 3 & 366 \\
\hline A12 & ADR & steel crates & 22,2 & High & 9 & 1917 \\
\hline A13 & ADR & cardboard boxes & 21,2 & Low & 2 & 432 \\
\hline A14 & ADR & rigid DPPL & 19,2 & High / Medium & 7 & 1012 \\
\hline A15 & ADR & elastic DPPL & 20,2 & Low & 2 & 342 \\
\hline A16 & ADR & plastic canisters & 31,2 & Medium & 5 & 579 \\
\hline
\end{tabular}

by the highest price per ton, as opposed to the alternatives where the cargo is transported in bulk, in an open container.

Subsequently, the expert's knowledge was used to divide the domain of each of the criteria to three triangular fuzzy numbers. The obtained division is expressed by (15):

$$
\begin{aligned}
& C_{1}=\{10,40,100\} \\
& C_{2}=\{0,5,10\} \\
& C_{3}=\{200,600,2000\}
\end{aligned}
$$

The triangular fuzzy numbers for the criteria $C_{1}-C_{3}$ are presented on Figures 2-4. The membership functions for the triangular fuzzy numbers short, medium and long for the criterion $C_{1}$ are defined in the equations (16)-(18) respectively. The membership functions for the TFNs for the criteria $C_{2}$ and $C_{3}$ can be defined in a similar manner.

$$
\begin{gathered}
\mu_{\text {short }}\left(C_{1}\right)= \begin{cases}1 & C_{1}=10 \\
\frac{40-C_{1}}{30} & 10 \leq C_{1} \leq 40 \\
0 & C_{1} \geq 40\end{cases} \\
\mu_{\text {medium }}\left(C_{1}\right)= \begin{cases}\frac{C_{1}-10}{30} & 10 \leq C_{1} \leq 40 \\
1 & C_{1}=40 \\
\frac{100-C_{1}}{60} & 40 \leq C_{1} \leq 100\end{cases} \\
\mu_{\text {long }}\left(C_{1}\right)= \begin{cases}0 & C_{1} \leq 40 \\
\frac{C_{1}-40}{60} & 40 \leq C_{1} \leq 100 \\
1 & C_{1}=100\end{cases}
\end{gathered}
$$

\section{Step 2: Generation of the Characteristic Objects}

The characteristic objects $O C_{1}-O C_{27}$ were generated as a Cartesian product of the fuzzy numbers' cores of each of the $C_{1}-C_{3}$ criteria. The obtained characteristic objects are presented in the first four columns of Table IV and depicted on Figure 5.

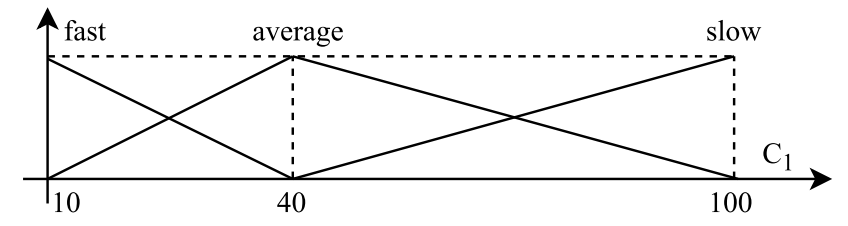

Fig. 2. The set of three triangular numbers for the transport time criterion $\left(C_{1}\right)$.

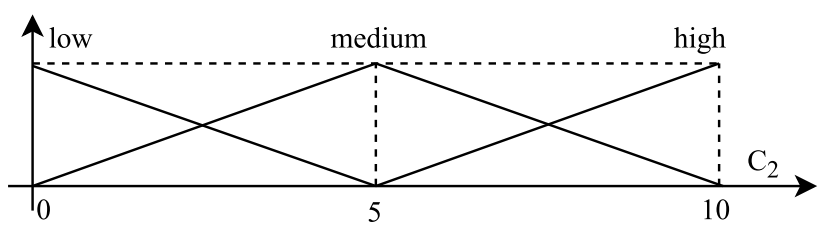

Fig. 3. The set of three triangular numbers for the transport safety criterion $\left(C_{2}\right)$.

\section{Step 3: Evaluation of the Characteristic Objects}

Subsequently, the expert performed a pairwise comparison of the characteristic objects. As a result, the Matrix of Expert Judgement $(M E J)$ was determined, where each $\alpha_{i j}$ value was calculated with the usage of (12). The $M E J$ matrix is depicted on Figure 6, where the $\alpha_{i j}$ values of $0,0.5$ and 1 are represented by white, black and grey boxes respectively.

Next, the vertical vector of the Summed Judgements $(S J)$ was calculated with the usage of (13). The $S J$ vertical vector is presented in the fifth column of Table IV. Eventually, the $S J$ vector was used to approximate the values of preference, which rendered the $P$ vertical vector of preference (see the sixth column of Table IV). 


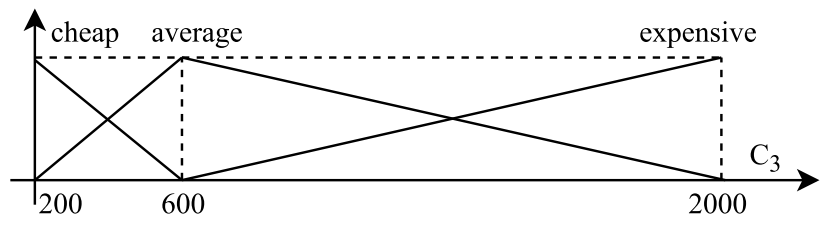

Fig. 4. The set of three triangular numbers for the transport cost criterion $\left(C_{3}\right)$.

TABLE IV

THE RESULTS OF THE COMET METHOD.

\begin{tabular}{|c|c|c|c|c|c|}
\hline$C O_{i}$ & $C_{1}$ & $C_{2}$ & $C_{3}$ & SJ & P \\
\hline$C O_{1}$ & 10 & 0 & 200 & 16.5 & 0.65 \\
\hline$C O_{2}$ & 10 & 0 & 600 & 14.5 & 0.55 \\
\hline$C O_{3}$ & 10 & 0 & 2000 & 5 & 0.15 \\
\hline$C O_{4}$ & 10 & 5 & 200 & 22 & 0.90 \\
\hline$C O_{5}$ & 10 & 5 & 600 & 20.5 & 0.85 \\
\hline$C O_{6}$ & 10 & 5 & 2000 & 13 & 0.45 \\
\hline$C O_{7}$ & 10 & 10 & 200 & 26.5 & 1.00 \\
\hline$C O_{8}$ & 10 & 10 & 600 & 23.5 & 0.95 \\
\hline$C O_{9}$ & 10 & 10 & 2000 & 15.5 & 0.60 \\
\hline$C O_{10}$ & 40 & 0 & 200 & 14 & 0.50 \\
\hline$C O_{11}$ & 40 & 0 & 600 & 11 & 0.40 \\
\hline$C O_{12}$ & 40 & 0 & 2000 & 3 & 0.10 \\
\hline$C O_{13}$ & 40 & 5 & 200 & 20 & 0.80 \\
\hline$C O_{14}$ & 40 & 5 & 600 & 15.5 & 0.60 \\
\hline$C O_{15}$ & 40 & 5 & 2000 & 7.5 & 0.20 \\
\hline$C O_{16}$ & 40 & 10 & 200 & 23.5 & 0.95 \\
\hline$C O_{17}$ & 40 & 10 & 600 & 19 & 0.85 \\
\hline$C O_{18}$ & 40 & 10 & 2000 & 10 & 0.35 \\
\hline$C O_{19}$ & 100 & 0 & 200 & 8 & 0.25 \\
\hline$C O_{20}$ & 100 & 0 & 600 & 7.5 & 0.20 \\
\hline$C O_{21}$ & 100 & 0 & 2000 & 0.5 & 0.00 \\
\hline$C O_{22}$ & 100 & 5 & 200 & 14 & 0.50 \\
\hline$C O_{23}$ & 100 & 5 & 600 & 10 & 0.35 \\
\hline$C O_{24}$ & 100 & 5 & 2000 & 2.5 & 0.05 \\
\hline$C O_{25}$ & 100 & 10 & 200 & 17.5 & 0.70 \\
\hline$C O_{26}$ & 100 & 10 & 600 & 15.5 & 0.60 \\
\hline$C O_{27}$ & 100 & 10 & 2000 & 8.5 & 0.30 \\
\hline & & & & \\
\hline
\end{tabular}

\section{Step 4: The rule base}

In the next step, each characteristic object and its performance was converted to a fuzzy rule with (6). A sample rule is presented below (19):

$$
\begin{array}{llllll}
R_{1}: & & & \\
I F & C_{1} \sim 10 & A N D & C_{2} \sim 0 & A N D & C_{3} \sim 200 \\
\text { THEN } & P \sim 0.65 & & & &
\end{array}
$$

\section{Step 5: Inference and the Final Evaluation}

In the last step of the model creation, each alternative was presented as a set of crisp numbers corresponding to the $C_{1}$ $C_{3}$ criteria. Mamdani's fuzzy inference method was used to compute the preference $P_{i}$ of each of the alternatives. The obtained $P$ vertical vector, along with the resulting ranks of the alternatives, are presented in Table $\mathrm{V}$.

According to the ranking generated by the COMET method, the $A_{9}$ alternative (i.e. ADR, cistern) is the best method of ammonium nitrate transport. It is fast, relatively cheap, and yet very safe. The second position was assigned to the $A_{10}$ alternative, i.e. ADR, in bulk, closed container. This type of container renders the alternative only slightly less safe, but the time of the transport is shorter and the price is lower than in the $A_{9}$ alternative. The $A_{1}$ alternative is the best one from the RID alternatives and has the fourth position in the ranking. It provides high safety and a lower price than the aforementioned alternatives, however the time of transport is significantly longer. The $A_{12}$ alternative, having the thirteenth position, is the worst one from the ADR group, and the $A_{4}$ alternative is considered to be the worst solution in the ranking. This is probably caused by the very high cost associated with the the steel crates' container type.

\section{Sensitivity analysis}

To verify the robustness of the obtained decision model, a sensitivity analysis was performed. Values of each of the $C_{1}$ $C_{3}$ criteria were increased by $1 \%$. The numeric and percentage difference between the original and the new $P_{i}$ values for each $A_{1}-A_{16}$ alternative were calculated. Table VI demonstrates the highest and the lowest changes of the $P$ value for all the $A_{1}$ $A_{16}$ alternatives. The absolute values of the percentage change vary from $0.0503 \%$ to $1.4602 \%$, thus confirming the stability of the obtained decision model.

\section{Comparison to a Linear Model}

In the last step of the research, a linear model was created on the basis of the characteristic objects, to verify how the simplification of the model would affect the results. The linear model results were compared to the COMET method results. The formula from equation (20) was used to calculate the $P_{i}^{\prime}$ value for each of the $A_{1}-A_{16}$ alternatives. The coefficient of determination $R^{2}$ is presented in equation (21) and its value suggests that the linear model fits the COMET model very well. The seventh column of Table $\mathrm{V}$ contains the $P^{\prime}$ vertical vector, and the eight column presents the difference between the preference calculated by the linear model and by the COMET method. As it can be noted, the difference between $P$ and $P^{\prime}$ for the $A_{12}$ alternative is equal to $6.91 \%$, which shows, that despite the $R^{2}$ value being very close to 1 , the linear model does not fit the COMET model perfectly well.

$$
P=0.5111-0.1453 \cdot C_{1}+0.1618 \cdot C_{2}-0.1966 \cdot C_{3}
$$

$$
R^{2}=0.9644
$$




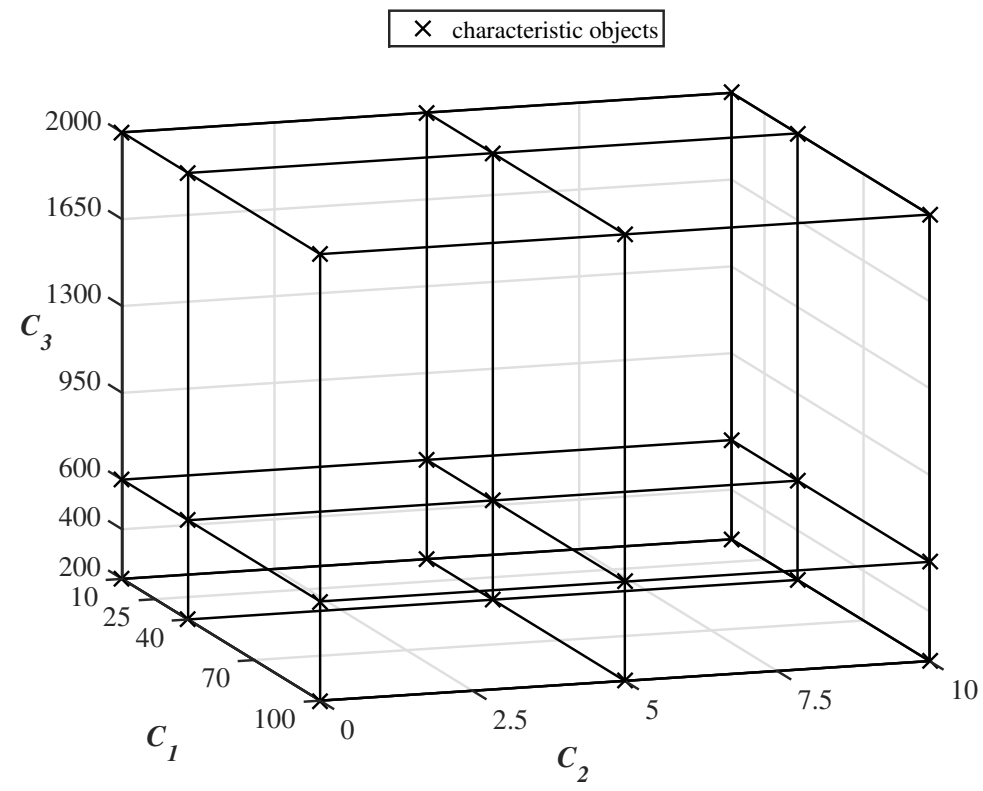

Fig. 5. Characteristic objects in the space of the problem

TABLE V

CONSIDERED ALTERNATIVES AND THEIR RESULTS

\begin{tabular}{|l|c|c|c|c|c|c|c|}
\hline$A_{i}$ & $C_{1}$ & $C_{2}$ & $C_{3}$ & $P$ & $P$ rank & $\mathrm{P}^{\prime}$ & diff \\
\hline$A_{1}$ & 79 & 9 & 320 & 0.7169 & 4 & 0.7095 & $-1.04 \%$ \\
\hline$A_{2}$ & 78.5 & 7 & 262 & 0.6585 & 8 & 0.6482 & $-1.57 \%$ \\
\hline$A_{3}$ & 78 & 5 & 252 & 0.5881 & 10 & 0.5748 & $-2.27 \%$ \\
\hline$A_{4}$ & 87 & 9 & 1837 & 0.3046 & 16 & 0.2998 & $-1.58 \%$ \\
\hline$A_{5}$ & 86 & 3 & 352 & 0.4191 & 15 & 0.4415 & $5.35 \%$ \\
\hline$A_{6}$ & 84 & 7 & 932 & 0.4367 & 14 & 0.4597 & $5.27 \%$ \\
\hline$A_{7}$ & 85 & 5 & 262 & 0.5498 & 11 & 0.5456 & $-0.76 \%$ \\
\hline$A_{8}$ & 96 & 7 & 498.6 & 0.5001 & 12 & 0.5223 & $4.45 \%$ \\
\hline$A_{9}$ & 14.2 & 9 & 426.4 & 0.9378 & 1 & 0.9298 & $-0.86 \%$ \\
\hline$A_{10}$ & 13.6 & 7 & 388 & 0.9007 & 2 & 0.8639 & $-4.09 \%$ \\
\hline$A_{11}$ & 13.2 & 3 & 366 & 0.7542 & 3 & 0.7154 & $-5.15 \%$ \\
\hline$A_{12}$ & 22.2 & 9 & 1917 & 0.4926 & 13 & 0.5267 & $6.91 \%$ \\
\hline$A_{13}$ & 21.2 & 2 & 432 & 0.6421 & 9 & 0.6295 & $-1.96 \%$ \\
\hline$A_{14}$ & 19.2 & 7 & 1012 & 0.7145 & 5 & 0.6866 & $-3.91 \%$ \\
\hline$A_{15}$ & 20.2 & 2 & 342 & 0.6702 & 7 & 0.6558 & $-2.15 \%$ \\
\hline$A_{16}$ & 31.2 & 5 & 579 & 0.6815 & 6 & 0.6713 & $-1.49 \%$ \\
\hline & & & & & \\
\hline
\end{tabular}

\section{CONCLusions}

The development of the agriculture and the increase of the demand for mineral fertilizers, ammonium nitrate being one of them, results in the intensification of the fertilizers' transport. Since the ammonium nitrate is classified as a hazardous material, there are many factors to consider when transporting it.

While many of the prior studies focused on the economic aspects of the problem, the MCDA methods allow to build transport management models that include the other, often conflicting, factors. The authors' contribution in this paper was to create a sustainable transportation management decision model that incorporates some of the aforementioned criteria, yet is not prone to the rank reversal problem. Furthermore, it was demonstrated that the COMET method can be successfully employed in the ammonium nitrate transport management decision problems scope.

The problem of ammonium nitrate transport management was described in the paper. A methodology of sustainable decision model creation with the usage of the fuzzy set theory and the COMET method was presented. Eventually, an experiment was performed to evaluate sixteen alternative 


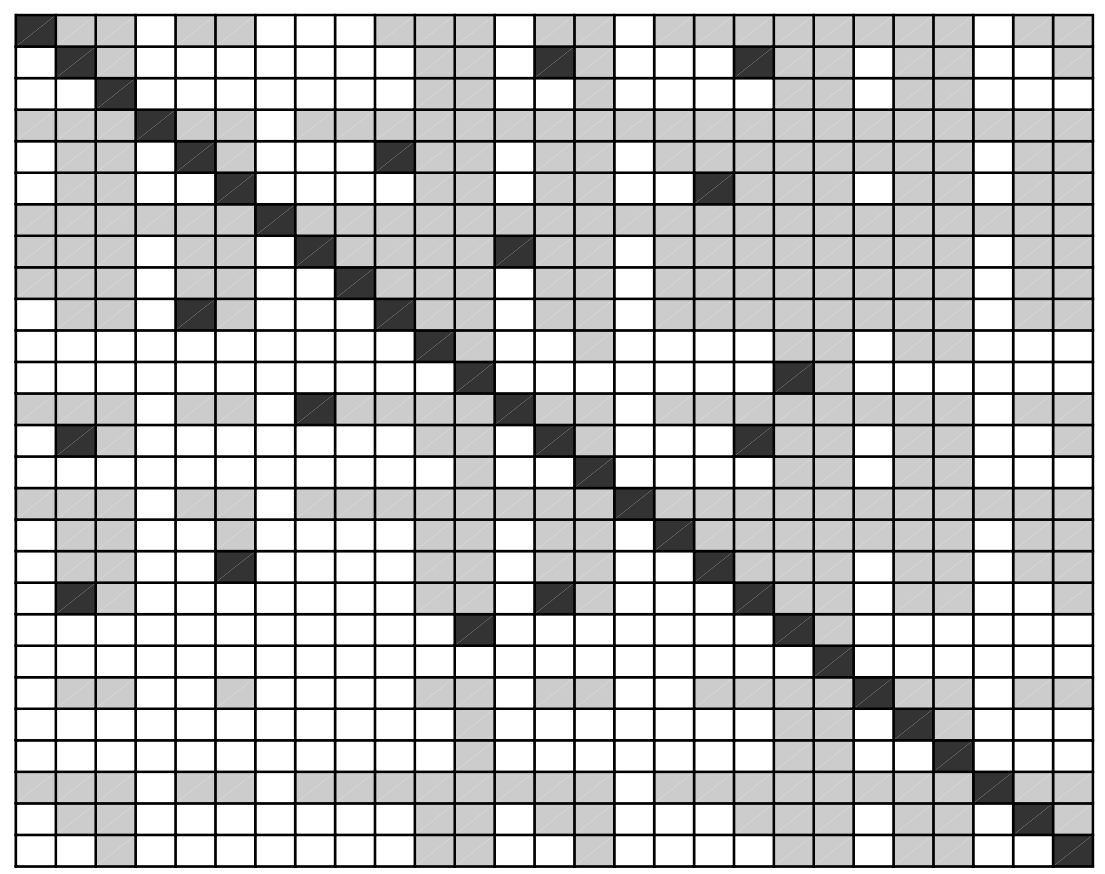

Fig. 6. The Matrix of Expert Judgement $(M E J)$.

TABLE VI

SENSITIVITY ANALYSIS FOR ALTERNATIVES ASSESSMENT IN RESPECT TO EACH CRITERION

\begin{tabular}{|l|c|c|c|c|c|c|}
\hline & \multicolumn{2}{|c|}{$C_{1}+1 \%$} & \multicolumn{2}{c|}{$C_{2}+1 \%$} & \multicolumn{2}{c|}{$C_{3}+1 \%$} \\
\hline & num. & per. & num. & per. & num. & per. \\
\hline min. change & -0.0005 & $-0.0503 \%$ & 0.0011 & $0.1592 \%$ & $-0,0006$ & $-0.0680 \%$ \\
\hline max. change & -0.0041 & $-0.8926 \%$ & 0.0042 & $1.3641 \%$ & -0.0056 & $-1.4602 \%$ \\
\hline
\end{tabular}

modes of the fertilizer transport on the route from Puławy to Gdańsk, based on the three most dominating ammonium nitrate transportation management criteria and the expert's knowledge.

In the first step of the experiment, the space of the problem was defined. Subsequently, the characteristic objects were generated. Next, the Matrix of Expert Judgment was created. In the fourth step, the rule base was defined, to allow to perform the inference and creation of the final ranking in the last step of the experiment. The robustness of the obtained ranking was then verified by the sensitivity analysis execution. Additionally, a linear model was created and its results were compared to the COMET ranking.

The research has identified possible areas of improvement and future work directions. This study was based on a set of the three dominating criteria, i.e. transport time, safety and cost. It would be beneficial to extend this set with additional criteria and thus create a complete hierarchy of ammonium nitrate transport management sustainable decisionmaking criteria. Furthermore, the hesitancy factors could be considered and a hesitant fuzzy version of the model could be created.

\section{ACKNOWLEDGMENT}

The work was supported by the National Science Centre, Decision No. DEC-2016/23/N/HS4/01931

\section{REFERENCES}

[1] M. A. Sutton, O. Oenema, J. W. Erisman, A. Leip, H. van Grinsven, and W. Winiwarter, "Too much of a good thing," Nature, vol. 472, no. 7342, pp. 159-161, 2011.

[2] Z. PANÁKOVÁ, P. SLAMKA, and O. LOŽEK, "Effect of nitrification inhibitors on the content of available nitrogen forms in the soil under maize (zea mays, 1.) growing," Journal of Central European Agriculture, vol. 17, no. 4, pp. 1013-1032, 2016.

[3] A. Oggero, R. Darbra, M. Munoz, E. Planas, and J. Casal, "A survey of accidents occurring during the transport of hazardous substances by road and rail," Journal of hazardous materials, vol. 133, no. 1, pp. 1-7, 2006.

[4] (1968, jan) 14. european agreement concerning the international carriage of dangerous goods by road (adr). [Online]. Available: https://treaties.un.org/Pages/ViewDetails.aspx?src=TREATY। \&mtdsg_no=XI-B-14\\&chapter=11\\&clang=_en

[5] (2017, jan) Regulations concerning the international carriage of dangerous goods by rail (rid). [Online]. Available: https://otif.org/ fileadmin/new/2-Activities/2D-Dangerous-Goods/RID_2017_E.pdf

[6] J. Wątróbski, "Outline of multicriteria decision-making in green logistics,” Transportation Research Procedia, vol. 16, pp. 537-552, 2016. 
[7] A. H. Vahabzadeh, A. Asiaei, and S. Zailani, "Green decision-making model in reverse logistics using fuzzy-vikor method," Resources, Conservation and Recycling, vol. 103, pp. 125-138, 2015.

[8] T. Litman, "Transportation cost and benefit analysis," Victoria Transport Policy Institute, vol. 31, 2009.

[9] C. Macharis and A. Bernardini, "Reviewing the use of multi-criteria decision analysis for the evaluation of transport projects: Time for a multi-actor approach," Transport policy, vol. 37, pp. 177-186, 2015.

[10] A. Tudela, N. Akiki, and R. Cisternas, "Comparing the output of cost benefit and multi-criteria analysis: An application to urban transport investments," Transportation Research Part A: Policy and Practice, vol. 40, no. 5, pp. 414-423, 2006.

[11] A. Alexander, H. Walker, and M. Naim, "Decision theory in sustainable supply chain management: a literature review," Supply Chain Management: An International Journal, vol. 19, no. 5/6, pp. 504-522, 2014.

[12] C. Macharis, L. Turcksin, and K. Lebeau, "Multi actor multi criteria analysis (mamca) as a tool to support sustainable decisions: State of use," Decision Support Systems, vol. 54, no. 1, pp. 610-620, 2012

[13] C. A. B. e Costa and P. Vincke, "Multiple criteria decision aid: an overview," in Readings in multiple criteria decision aid. Springer, 1990, pp. 3-14.

[14] J. Spronk, R. E. Steuer, and C. Zopounidis, "Multicriteria decision aid/analysis in finance," in Multiple Criteria Decision Analysis. Springer, 2016, pp. 1011-1065.

[15] C. Zopounidis, "The european school of mcda: Some recent trends," in Multicriteria Analysis. Springer, 1997, pp. 608-616.

[16] B. Matarazzo, "A pairwise criterion comparison approach: the mappac and pragma methods," in Readings in multiple criteria decision aid. Springer, 1990, pp. 253-273.

[17] B. Roy and D. Vanderpooten, "The european school of mcda: Emergence, basic features and current works," Journal of Multi-Criteria Decision Analysis, vol. 5, no. 1, pp. 22-38, 1996.

[18] J. Geldermann and O. Rentz, "Bridging the gap between american and european madm-approaches," in Proc. of the 51st Meeting of the European Working Group âĂIJMulticriteria Aid for DecisionsâĂ Madrid, 2000.

[19] J. R. S. C. Mateo, "Multi-attribute utility theory," in Multi Criteria Analysis in the Renewable Energy Industry. Springer, 2012, pp. 63-72.

[20] R. L. Keeney and H. Raiffa, Decisions with multiple objectives: preferences and value trade-offs. Cambridge university press, 1993.

[21] T. L. Saaty, "Decision making with the analytic hierarchy process," International journal of services sciences, vol. 1, no. 1, pp. 83-98, 2008

[22] T. L. Saaty, "The analytic network process," Pittsburgh: RWS Publications, 1996.

[23] T. Starfield, "Simple multi-attribute ranking technique smart," 2005.

[24] E. Jacquet-Lagrèze and J. Siskos, "Assessing a set of additive utility functions for multicriteria decision-making, the uta method," European journal of operational research, vol. 10, no. 2, pp. 151-164, 1982.

[25] C. A. Bana e Costa, J.-M. Corte, and J.-C. Vansnick, "Macbeth (measuring attractiveness by a categorical based evaluation technique)," Wiley Encyclopedia of Operations Research and Management Science, 2011.

[26] M. E. Baltazar, J. Jardim, P. Alves, and J. Silva, "Air transport performance and efficiency: Mcda vs. dea approaches," Procedia-Social and Behavioral Sciences, vol. 111, pp. 790-799, 2014.

[27] M. Miranda, M. E. Baltazar, and J. Silva, "Airlines performance and eflciency evaluation using a mcda methodology. the case for low cost carriers vs legacy carriers," Open Engineering, vol. 6, no. 1, 2016.

[28] Y.-J. Lai, T.-Y. Liu, and C.-L. Hwang, "Topsis for modm," European Journal of Operational Research, vol. 76, no. 3, pp. 486-500, 1994

[29] J. Figueira, V. Mousseau, and B. Roy, "Electre methods," in Multiple criteria decision analysis: State of the art surveys. Springer, 2005, pp. 133-153.

[30] K. Govindan and M. B. Jepsen, "Electre: A comprehensive literature review on methodologies and applications," European Journal of Operational Research, vol. 250, no. 1, pp. 1-29, 2016.

[31] J.-P. Brans and B. Mareschal, "Promethee methods," in Multiple criteria decision analysis: state of the art surveys. Springer, 2005, pp. 163-186.

[32] G. Munda, Multicriteria evaluation in a fuzzy environment: theory and applications in ecological economics. Springer Science \& Business Media, 2012.

[33] H. Pastijn and J. Leysen, "Constructing an outranking relation with oreste," Mathematical and Computer Modelling, vol. 12, no. 10-11, pp. 1255-1268, 1989.
[34] E. Hinloopen, P. Nijkamp, and P. Rietveld, "The regime method: A new multicriteria technique," in Essays and surveys on multiple criteria decision making. Springer, 1983, pp. 146-155.

[35] W. S. De Keyser and P. Peeters, "ArgusâĂ ̌̆a new multiple criteria method based on the general idea of outranking," in Applying multiple criteria aid for decision to environmental management. Springer, 1994 pp. 263-278.

[36] J.-M. Martel and B. Matarazzo, "Other outranking approaches," in Multiple criteria decision analysis: state of the art surveys. Springer, 2005, pp. 197-259.

[37] J. Leclercq, "Propositions dâĂŹextension de la notion de dominance en présence de relations dâĂŹordre sur les pseudo-critères: Melchior," Revue Belge de Recherche Opérationnelle, de Statistique et dâÁŹInformatique, vol. 24, no. 1, pp. 32-46, 1984.

[38] M. Bélanger and J.-M. Martel, "An automated explanation approach for a decision support system based on mcda." ExaCt, vol. 5, p. 04, 2005.

[39] H. Voogd, "Multicriteria evaluation with mixed qualitative and quantitative data," Environment and Planning B: Planning and Design, vol. 9, no. 2, pp. 221-236, 1982

[40] J. H. Paelinck, "Qualiflex: a flexible multiple-criteria method," Economics Letters, vol. 1, no. 3, pp. 193-197, 1978.

[41] A. Giarlotta, "Passive and active compensability multicriteria annalysis(pacman)," Journal of Multi-Criteria Decision Analysis, vol. 7, no. 4, pp. 204-216, 1998

[42] S. Greco, "A new pcca method: Idra," European Journal of Operational Research, vol. 98, no. 3, pp. 587-601, 1997.

[43] A. Piegat and W. Sałabun, "Identification of a multicriteria decisionmaking model using the characteristic objects method," Applied Computational Intelligence and Soft Computing, vol. 2014, p. 14, 2014.

[44] P. Fortemps, S. Greco, and R. Słowiński, "Multicriteria choice and ranking using decision rules induced from rough approximation of graded preference relations," in International Conference on Rough Sets and Current Trends in Computing. Springer, 2004, pp. 510-522.

[45] P. Ferrari, "A method for choosing from among alternative transportation projects," European Journal of Operational Research, vol. 150, no. 1, pp. 194-203, 2003

[46] K. Poh and B. Ang, "Transportation fuels and policy for singapore: an ahp planning approach," Computers \& industrial engineering, vol. 37, no. 3, pp. 507-525, 1999.

[47] V. P. Darji and R. V. Rao, "Application of ahp/evamix method for decision making in the industrial environment," American Journal of Operations Research, vol. 3, no. 06, p. 542, 2013.

[48] G.-H. Tzeng, C.-W. Lin, and S. Opricovic, "Multi-criteria analysis of alternative-fuel buses for public transportation," Energy Policy, vol. 33, no. 11, pp. 1373-1383, 2005.

[49] S. Jharkharia and R. Shankar, "Selection of logistics service provider: An analytic network process (anp) approach," Omega, vol. 35, no. 3 , pp. 274-289, 2007.

[50] O. Bayazit, "Use of analytic network process in vendor selection decisions," Benchmarking: An International Journal, vol. 13, no. 5, pp. 566-579, 2006

[51] U. Tuzkaya, "Evaluating the environmental effects of transportation modes using an integrated methodology and an application," Interna tional Journal of Environmental Science \& Technology, vol. 6, no. 2, pp. 277-290, 2009.

[52] E. Bottani and A. Rizzi, "A fuzzy topsis methodology to support outsourcing of logistics services," Supply Chain Management: An International Journal, vol. 11, no. 4, pp. 294-308, 2006.

[53] A. Awasthi, S. S. Chauhan, and S. K. Goyal, "A multi-criteria decision making approach for location planning for urban distribution center under uncertainty," Mathematical and Computer Modelling, vol. 53, no. 1, pp. 98-109, 2011.

[54] H. Jafari, "Presenting an integrative approach of mappac and fanp and balanced scorecard for performance measurements of container terminals," International Journal of Basic Sciences \& Applied Research, vol. 2, no. 4, pp. 494-504, 2013.

[55] C. Delhaye, J. Teghem, and P. Kunsch, "Application of the oreste method to a nuclear waste management problem," International Journal of Production Economics, vol. 24, no. 1-2, pp. 29-39, 1991

[56] X. Wang and H. K. Chan, "A hierarchical fuzzy topsis approach to assess improvement areas when implementing green supply chain initiatives," International Journal of Production Research, vol. 51, no. 10, pp. 3117 3130, 2013. 
[57] K. Govindan, S. Rajendran, J. Sarkis, and P. Murugesan, "Multi criteria decision making approaches for green supplier evaluation and selection: a literature review," Journal of Cleaner Production, vol. 98, pp. 66-83, 2015.

[58] W. Ho, X. Xu, and P. K. Dey, "Multi-criteria decision making approaches for supplier evaluation and selection: A literature review," European Journal of operational research, vol. 202, no. 1, pp. 16-24, 2010.

[59] S. Faizi, T. Rashid, W. Sałabun, S. Zafar, and J. Wątróbski, "Decision making with uncertainty using hesitant fuzzy sets," International Journal of Fuzzy Systems, pp. 1-11, 2017.

[60] W. Sałabun, P. Ziemba, and J. Wątróbski, "The rank reversals paradox in management decisions: The comparison of the ahp and comet methods," in Intelligent Decision Technologies 2016. Springer, 2016, pp. 181-191.

[61] L. A. Zadeh, "Fuzzy sets," Information and control, vol. 8, no. 3, pp. 338-353, 1965

[62] F. T. Chan and N. Kumar, "Global supplier development considering risk factors using fuzzy extended ahp-based approach,” Omega, vol. 35, no. 4, pp. 417-431, 2007.

[63] K. Govindan, R. Khodaverdi, and A. Jafarian, "A fuzzy multi criteria approach for measuring sustainability performance of a supplier based on triple bottom line approach," Journal of Cleaner Production, vol. 47, pp. $345-354,2013$.

[64] S. Önüt, S. S. Kara, and E. Işik, "Long term supplier selection using a combined fuzzy mcdm approach: A case study for a telecommunication company," Expert systems with applications, vol. 36, no. 2, pp. 3887 3895, 2009.

[65] W. Sałabun, "Application of the fuzzy multi-criteria decision-making method to identify nonlinear decision models," Int. J. Comput. Appl, vol. 89 , no. 15 , pp. 1-6, 2014.

[66] W. Sałabun, "Reduction in the number of comparisons required to create matrix of expert judgment in the comet method," Management and Production Engineering Review, vol. 5, no. 3, pp. 62-69, 2014.

[67] W. Sałabun, "The characteristic objects method: A new distance-based approach to multicriteria decision-making problems," Journal of MultiCriteria Decision Analysis, vol. 22, no. 1-2, pp. 37-50, 2015.

[68] W. Pedrycz, P. Ekel, and R. Parreiras, Fuzzy multicriteria decisionmaking: models, methods and applications. John Wiley \& Sons, 2011.

[69] A. Piegat, "Fuzzy modeling and control (studies in fuzziness and soft computing)," Physica, p. 742, 2001.

[70] T. J. Ross, "Properties of membership functions, fuzzification, and defuzzification," Fuzzy Logic with Engineering Applications, Third Edition, pp. 89-116, 2010.

[71] A. Piegat and W. Sałabun, "Comparative analysis of mcdm methods for assessing the severity of chronic liver disease," in International Conference on Artificial Intelligence and Soft Computing. Springer, 2015, pp. 228-238. 